\title{
Colorectal Cancer Screening Compliance and Contemplation in Gynecology Patients
}

\author{
Stacy B. Menees, M.D., John Inadomi, M.D., ${ }^{2}$ Grace Elta, M.D., Sheryl Korsnes, M.A., \\ Margaret Punch, M.D., and Leslie Aldrich, M.D.
}

Abstract

Objective: Colorectal cancer screening (CRCS) should be a necessary part of gynecology (GYN) providers' preventive practices. The purpose of our study is to examine CRCS recommendations and adherence in this population.

Methods: A questionnaire was administered to a prospective cohort of patients awaiting health maintenance exams at six academic and private gynecology offices. Patients reported demographics, CRC/breast/cervical screening adherence, CRCS recommendations, and future likelihood of CRCS.

Results: A total of 461 women aged 51 years and older completed the questionnaire. Sixty-six percent of respondents were compliant with CRCS compared to $93 \%$ and $86 \%$ for breast and cervical cancer screening, respectively $(p<0.001)$. GYN providers recommended CRCS in $43 \%$ of patients. Sixty-three percent were planning to undergo future CRCS. On multivariable analysis, characteristics associated with CRCS adherence included (odds ratio, 95\% confidence interval): older age (1.1 per year, 1.1-1.2), previous mammography (3.7, 1.4-9.7), family history (FH) of CRC/polyps (1.9, 1.0-3.4), friend with CRC (2.6, 1.5-4.7), and any doctor recommending CRCS $(8.2,4.6-14.7)$. CRCS rates were higher among patients who received a recommendation from a PCP (primary care provider) than from a GYN provider. Factors associated with intention to undergo CRCS include previous mammography (1.4, 4.2-12.0), any doctor recommendation (6.4, 3.7-11.0), and FH of CRC/polyps $(3.5,1.9-6.3)$. CRCS recommendations by both GYNs and PCPs had a greater impact on CRCS contemplation than those from a PCP or GYN alone.

Conclusion: In gynecology patients, having multiple providers recommend CRCS increases the likelihood of patients' intentions to undergo CRCS. However, CRCS compliance is primarily driven solely by PCP recommendations. Regardless, strategies must be in place to prompt gynecologists and nurse practitioners to discuss CRCS in eligible patients.

\section{Introduction}

I N 2008, it is expected that colorectal cancer (CRC) will account for 148,810 new diagnoses and 49,960 deaths. ${ }^{1}$ Despite the implementation of CRC screening guidelines published jointly since 1997 by the American College of Gastroenterology, the U.S. Preventive Services Task Force and the American Cancer Society, patient compliance for CRC screening remains suboptimal. ${ }^{2-4}$ Data from the Behavioral Risk Factor Surveillance System (BRFSS) revealed that only $57 \%$ of the U.S. population is adherent to CRC screening guidelines. $^{5}$
In order to improve CRC screening compliance, we must investigate all populations in the primary care realm. For women, gynecologists are an important source of primary care, particularly for annual preventive care. Their gynecologist may be the only physician that they come into contact with. Anywhere between 37 to $93 \%$ of obstetrician/gynecologists (ob/gyn) consider themselves to be primary care health providers. $^{6-8}$ The National Ambulatory Medical Care Survey (NAMCS) and the National Hospital Ambulatory Care Survey (NHACS) collected information on care provided by office-based physicians and outpatient clinics in a nationally representative sample of healthcare visits and showed that

\footnotetext{
${ }^{1}$ Division of Gastroenterology, University of Michigan, Ann Arbor, Michigan.

${ }^{2}$ Division of Gastroenterology, University of California-San Francisco, San Francisco, California.

${ }^{3}$ Division of Obstetrics/Gynecology, University of Michigan, Ann Arbor, Michigan.
} 
primary care visits to obstetricians/gynecologists account for 45 million office visits and 4 million outpatient clinic visits. ${ }^{9}$ The Residency Review Committee for Obstetrics-Gynecology recognized this important finding and recommended a minimum of 6 months of primary care within 4 years of obstetrics/gynecology residency training, which was implemented by the Accreditation Council for Graduate Medical Education in $1996 .^{10}$

As a part of the annual maintenance examination for $\mathrm{Ob} /$ Gyn, CRC screening should be addressed in age-appropriate women. ${ }^{11}$ However, few studies in the gynecology literature have addressed CRC screening adherence in their patients. One study revealed the primary method of CRC screening by obstetricians/gynecologists was flexible sigmoidoscopy, followed by a fecal occult blood test (FOBT). ${ }^{12}$ Data collected from the National Heath Interview Survey reported that $43 \%$ of women aged 50-64 seeing gynecologists underwent colorectal cancer screening, compared to cervical cancer screening and mammography at $97 \%$ and $90.9 \%$, respectively. ${ }^{13}$ With more reliable techniques that have proven effective in reducing colon cancer mortality, it is necessary to focus our efforts on this population to evaluate their CRC screening adherence, and thus possibly improve the overall CRC screening rate. ${ }^{14-22}$

The aims of this study were to compare rates of adherence to screening for CRC versus other malignancies recommended for women seen in gynecology clinics for routine health maintenance exams, and to examine the effect of CRC screening recommendations from gynecology and other providers on current adherence and intention to undergo CRC screening in the future.

\section{Methods}

This study was conducted in Ann Arbor, Michigan, at three outpatient clinics in the University of Michigan Health System and three unaffiliated, private obstetrics/gynecology clinics in the Detroit metropolitan area. The three outpatient academic clinics represent 24 providers. Two of the three private clinics were single specialty; the remaining practice was multispecialty, representing 10 providers in all. With institutional review board approval, female patients were solicited for enrollment in the offices' waiting room prior to routine health maintenance examinations (HME). Patients were consecutively enrolled among all eligible patients seen in each clinic setting. Appointments with both board-certified gynecologists and nurse-practitioners (NP) (collectively, GYN providers) were included, since nurse-practitioners are utilized as physician extenders in ob/gyn practices and routinely perform HMEs. Resident clinics were specifically not solicited. Participants aged 51 and older were eligible for participation. Participating subjects were required to have an established relationship with the practice, which was defined by at least one health maintenance appointment in the preceding year. Exclusion criteria included new patients and gastrointestinal disorders requiring periodic endoscopic surveillance of the colon.

Our planned sample size of 400 subjects was based on an alpha of 0.05 , with a $95 \%$ power to detect a $10 \%$ difference in adherence between CRC screening and breast or cervical cancer screening.

Consenting subjects completed an anonymous survey based on constructs from validated surveys and in our pre- vious work. ${ }^{23,24}$ (Appendix 1) Patient demographic data were obtained including the subjects' age, and marital and employment status. The patients' insurance status, gender, and type of practitioner were also noted. Participants were asked whether they considered their GYN provider to be their primary care provider. Current CRC screening status (adherence) was assessed at the time of the survey if they had completed FOB testing in the last 12 months, a flexible sigmoidoscopy or double contrast barium enema in the last five years, or colonoscopy in the last ten years. Questions assessing adherence to other preventive health behaviors, i.e., breast and cervical cancer screening, were included. Participants were specifically asked if their GYN provider, PCP, or another physician had recommended CRC screening. We also assessed the subjects' intentions to undergo CRC screening in the future. Personal experience with CRC was derived from the subjects' personal knowledge of someone with CRC and a family history of CRC.

\section{Statistical Analysis}

The response rate was defined as the ratio between the number of subjects who completed the entire study survey and the number of patients solicited for entry in the study. Chi-square or Student's $t$-test were used to assess the relationship between the independent variable (recommendation of CRC screening) and the dependent variables (current CRC screening adherence and intended future CRCS screening), in addition to a comparison of screening rates between CRC and cervical or breast cancer. The following variables were utilized for both univariate analyses: insurance, age, female/ male physician, each type of ethnicity, marital status, employment status, gynecologist only, PCP only, gynecologist plus PCP, previous mammography cervical cancer screening, and previous CRC screening. The multivariable regression analysis was used to simultaneously adjust the model for the effects of independent variables that were identified to be significantly associated in univariate analysis $(p<0.05)$. In the multivariable regression analysis, $p$ values $<0.05$ were considered significant, and the results are presented as odds ratios with $95 \%$ confidence intervals.

\section{Results}

\section{Characteristics of the study population}

A total of 461 women were solicited and enrolled in the study at the time of their health maintenance exam. Complete data were available for 438 participants (95\% response rate). The majority of participants were seen by ob/gyns (72\%) with the remaining patients seen by nurse-practitioners. Characteristics of the study population are described in Table 1. Overall, most respondents were Caucasian (90\%), married (69\%), and employed (61\%). The mean age was $58 \pm 6.7$ years. Fifty-three percent were participants from an academic practice. Twenty-one percent of subjects identified their GYN as their primary care provider.

\section{CRC screening recommendations}

Forty-three percent of participants reported CRC screening recommendations from their GYN provider. The private population that we surveyed reported a CRC screening recommendation rate of $47 \%$ vs. $40 \%$ in the academic population. 
Table 1. Characteristics of the Study POPUlation $(n=461)$

\begin{tabular}{lcc}
\hline Characteristic & $\begin{array}{c}\text { Academic } \\
(\mathrm{n}=244)\end{array}$ & $\begin{array}{c}\text { Private Practice } \\
(\mathrm{n}=217)\end{array}$ \\
\hline Race & & \\
Caucasian & $223(91 \%)$ & $191(88 \%)$ \\
Other & $21(9 \%)$ & $26(12 \%)$ \\
Age (years) & & \\
$\quad$ mean (SD) & $59.3(7.4)$ & $57.1(5.7)$ \\
Marital status & & \\
$\quad$ Married & $151(62 \%)$ & $168(77 \%)$ \\
Practitioner type seen & & \\
Female gynecologist & $78(32 \%)$ & $165(76 \%)$ \\
Male gynecologist & $78(32 \%)$ & $10(5 \%)$ \\
Female NP & $84(34 \%)$ & $37(17 \%)$ \\
Male NP & $1(<1 \%)$ & $4(2 \%)$ \\
Employment status & $144(59 \%)$ & $139(64 \%)$ \\
Working & $68(28 \%)$ & $55(25 \%)$ \\
Retired & $25(10 \%)$ & $20(9 \%)$ \\
Unemployed & $7(3 \%)$ & 0 \\
Other & & \\
Preventive practices & $186(76 \%)$ & $120(55 \%)$ \\
Colorectal cancer & $230(94 \%)$ & $199(91 \%)$ \\
Mammography & $198(81 \%)$ & $171(79 \%)$ \\
PAP smear &
\end{tabular}

Numbers may not equal $100 \%$ due to multiple or missing answers by respondents.

$\mathrm{NP}$, nurse-practitioner.

Overall, $75 \%$ of participants reported a previous CRC screening recommendation from any physician. Fifty-nine percent of participants reported that their PCP had given them a prior CRC screening recommendation.

\section{CRC screening adherence}

Sixty-six percent of all respondents stated prior compliance with one or more CRC screening modalities, which was significantly lower than compliance to breast (93\%) and cervical cancer screening (86\%, $p<0.001$ for all comparisons). Participants were more compliant with CRC screening in the academic setting $(76 \%)$ vs. the private setting (55\%). Colonoscopy $(53 \%)$ was the most frequently utilized modality for participants. An additional $17.5 \%$ and $11.5 \%$ had fecal occult stool and flexible sigmoidoscopy performed, respectively. Of the $43 \%$ of subjects who reported that their gynecologists advised them to undergo CRC screening, $76 \%$ of these patients were adherent for CRC screening.

\section{Predictors of CRC screening adherence}

Significant patient characteristics predictive of CRC screening adherence at the time of the survey in multivariable analysis (Table 2) included older age, previous mammography, family history of CRC/polyps, a friend with CRC, and any physician (defined as GYN provider, internal medicine/ family practice, or other physician) recommending CRC screening. CRCS rates were higher among patients who received a recommendation from a PCP than from a GYN provider Patients in the academic setting were two-fold more likely than those in nonacademic settings to have previously undergone any CRC screening test at the time of the survey.
Table 2. Multivariable Analysis: Correlates of Colorectal Cancer Screening Adherence

\begin{tabular}{llc}
\hline Characteristic & Odds ratio & $\begin{array}{c}95 \% \text { Confidence } \\
\text { interval }\end{array}$ \\
\hline Age & 1.1 per year & $1.1-1.2^{\mathrm{a}}$ \\
Previous mammography & 3.7 & $1.4-9.7^{\mathrm{a}}$ \\
FH of CRC/polyps & 1.9 & $1.0-3.4^{\mathrm{a}}$ \\
Friend with CRC & 2.6 & $1.5-4.7^{\mathrm{a}}$ \\
Any physician & 8.2 & $4.6-14.7^{\mathrm{a}}$ \\
$\quad$ recommendation & & \\
Specific physician & 3.2 & $1.8-5.6^{\mathrm{a}}$ \\
$\quad$ PCP & 1.1 & $0.5-2.1$ \\
$\quad$ Gyn provider & 1.4 & $0.8-2.5$ \\
$\quad$ Gyn + PCP & & $1.2-3.3^{\mathrm{a}}$ \\
Practice Setting & 2.0 & \\
Academic & & \\
\hline
\end{tabular}

aSignificant variables.

$\mathrm{FH}$, family history; $\mathrm{CRC}$, colorectal cancer; $\mathrm{PCP}$, primary care provider; Gyn, gynecology.

\section{Future CRC screening}

Sixty-three percent of respondents were planning to undergo CRC screening in the future. In those participants who had undergone CRC screening previously, $72 \%$ planned future CRC screening vs. $51 \%$ of respondents who had not undergone CRC screening at the time of the HME. Predictors of intention to screen in the future (Table 3) in the multivariable analysis include previous mammography, any doctor recommendation, and $\mathrm{FH}$ of $\mathrm{CRC} /$ polyps. CRC screening recommendations by both GYN providers and PCPs had a greater impact on future CRC screening contemplation than those from a PCP or GYN provider alone. There was no difference in participants' likelihood to undergo future CRC screening based on practice setting.

\section{Discussion}

Despite preventive modalities that have been shown to reduce CRC mortality, CRC screening adherence remains low. This study examined CRC screening recommendations from different providers, and adherence and intention to undergo CRC screening in the future among gynecology patients at the time of their HME. Our findings demonstrate a CRC screening rate for our population that is better than the

Table 3. Multivariable Analysis: CORRElATES OF INTENTION TO UNDERGO Colorectal Cancer Screening

\begin{tabular}{llc}
\hline Characteristic & $\begin{array}{c}\text { Odds } \\
\text { ratio }\end{array}$ & $\begin{array}{c}95 \% \text { Confidence } \\
\text { interval }\end{array}$ \\
\hline $\begin{array}{l}\text { Previous mammography } \\
\text { FH of CRC/polyps }\end{array}$ & 1.4 & $4.2-12.0^{\mathrm{a}}$ \\
Any physician recommendation & 3.5 & $1.9-6.3^{\mathrm{a}}$ \\
Specific physician & 6.4 & $3.7-11.0^{\mathrm{a}}$ \\
PCP & 1.8 & $1.1-2.9^{\mathrm{a}}$ \\
$\quad$ Gyn provider & 1.5 & $0.8-3.03$ \\
$\quad$ Gyn + PCP & 3.06 & $1.7-5.3^{\mathrm{a}}$ \\
Practice setting & & \\
$\quad$ Academic & 1.15 & $0.8-1.7$ \\
\hline
\end{tabular}

\footnotetext{
${ }^{\mathrm{a}}$ Significant variables.
} 
national average; however, CRC screening adherence was significantly lower than adherence to breast and cervical cancer screening.

Only slightly more than $40 \%$ of women reported CRC screening recommendations from their gynecologic provider. In past studies, GYN providers have been shown to be less likely to recommend CRC screening than internists and family practitioners. ${ }^{25,26}$ Possibly the routine use of a FOBT during the gynecologic examination was felt to obviate the need for GYN providers to discuss CRC screening. Musinski demonstrated that $37 \%$ of patients being seen for a HME had a FOBT with the examiner's glove as their only source for CRC screening. ${ }^{12}$ In a recent survey of gynecologists and nursepractitioners, FOBT was the preferred CRC screening modality, with $30 \%$ using in-office single FOBT solely. Collins et al. demonstrated that only $4.9 \%$ of patients with cancer or large polyps had a positive FOBT from a single sample of stool obtained during the rectal examination, emphasizing that a single FOBT performed in the office via digital rectal exam is not an acceptable CRC screening option. ${ }^{27}$ Regardless, close to $60 \%$ of our cohort reported no CRC screening recommendations from their GYN provider. This is important given that one in five women considered their GYN provider to be their only source for preventive care.

The likelihood of prior and intention to undergo future CRC screening at the time of the survey was directly correlated with physician recommendation. Several studies have cited physician recommendation as an important factor influencing a patient decision to undergo CRC screening. ${ }^{28-34}$ Weitzman et al. demonstrated that persistent recommendations and a strong personal directive from a physician increased the use of FOBT and flexible sigmoidoscopy, even overcoming reluctance for screening. ${ }^{34}$ In women aged 50 to 80, Mandelson et al demonstrated that physician encouragement was the strongest factor related to participation in CRC screening. ${ }^{30}$ Interestingly, increased CRC screening adherence was seen with a specific type of provider in our study. Patients were particularly adherent when their PCP recommended CRC screening. Our finding may be secondary to patients' visiting their PCP more often than their gynecologist, thus giving the PCP more opportunity for CRC prevention. This demonstrates that the usual source of care is crucial for CRC screening adherence. ${ }^{35,36}$ Additionally, the PCPs in our study may have had a better infrastructure for scheduling CRC screening modalities, thus improving their effectiveness in CRC screening adherence. More importantly, our study demonstrates the additive effect of multiple CRC screening recommendations by different providers on future CRC screening contemplation. Data from the National health Interview Survey were consistent with our findings that the combination of general medical physician and gynecologist care increased the probability of women receiving CRC screening. ${ }^{13}$ This reiterates the need for all physicians to take advantage of every patient contact and seize this teachable moment to prompt individuals to undergo CRC screening and enhance compliance.

In our subjects, other positive predictors for current CRC screening adherence and intention to undergo future CRC screening included family history of CRC or a patient's knowledge of someone with CRC or both. Our findings are consistent with data reported in the literature. ${ }^{32,36-43}$ The strongest data comes from three multivariable analyses. ${ }^{31,38,43}$
Codori et al. demonstrated that the extent of family history with the number and proportion of first-degree relatives was predictive of endoscopic screening. ${ }^{38}$ In a survey of subjects with a first-degree relative of CRC, Harris and Byles showed that having more than one relative with colorectal cancer and being a sibling of the relative with colon cancer were associated with compliance with any of the accepted CRC screening modalities. ${ }^{37}$ Finally, Manne et al. demonstrated that CRC screening compliance was associated with the closeness of the emotional tie with the affected sibling. ${ }^{43}$ It was postulated that the closer the relationship with the affected sibling, the more likely the affected sibling would advise CRC screening and the more likely the healthy sibling would be influenced by this recommendation.

Previous studies have demonstrated that other non-CRCrelated screening tests, such as mammography, Pap smear, and prostate-specific antigen utilization within the past year, are associated with improved CRC screening among patients. ${ }^{41,44-46}$ In our population, both mammography and cervical screening were predictive of CRC screening on univariate analysis. However, adjusting for other predictive factors, only mammography remained significant. Nationally, our mammography compliance rate far exceeded the data from the 2006 BRFSS, which reported a 79.9\% compliance rate for mammography in women aged 50 and older. ${ }^{47}$

Our study has several notable potential limitations. The primary limitation of our study is that it relied on participant self-report; therefore, recall bias may be introduced by the study design. Participants may have overestimated their $\mathrm{CRC}$, breast, and cervical cancer screening compliance rates. Additionally, patients may have incorrectly recalled their discussions regarding CRC screening with their providers. In our patient population we did not assess the lifetime experience for CRC screening. We only assessed the participants' current CRC screening adherence at the time of the survey. Factors related to future CRC screening in the adherent vs. ever undergoing some type of CRC screening vs. those who have not undergone CRC screening may be different. This is an area for future study. Lastly, our study may not be able to be generalized to all women since our population was fairly homogenous and our sample was obtained at both academic offices and specific private practice offices that were willing to participate with the study.

In summary, among patients attending outpatient gynecology appointments, adherence to CRC screening is significantly lower than to breast and cervical cancer screening. Having multiple providers recommend CRC screening increases gynecology patients' likelihood of undergoing future CRC screening. However, CRC screening compliance is primarily driven solely by PCP recommendations. Regardless, strategies must be in place to prompt gynecologists and nurse-practitioners to discuss CRC screening in eligible patients. With new efforts, gynecologists may help improve CRC screening compliance in their female patients.

\section{Disclosure Statement}

The authors have no conflicts of interest to report.

\section{References}

1. Jemal A, Siegel R, Ward E, et al. Cancer statistics, 2008. CA Cancer J Clin 2008;58:71-96. 
2. Winawer SJ, Fletcher RH, Miller L, et al. Colorectal cancer screening: clinical guidelines and rationale. Gastroenterology 1997;112:594-642.

3. Winawer S, Fletcher R, Rex D, et al. Colorectal cancer screening and surveillance: clinical guidelines and rationale; update based on new evidence. Gastroenterology 2003;124: 544-560.

4. Levin B, Lieberman DA, McFarland B, et al. Screening and surveillance for the early detection of colorectal cancer and adenomatous polyps, 2008: a joint guideline from the American Cancer Society, the US Multi-Society Task Force on Colorectal Cancer, and the American College of Radiology. CA Cancer J Clin 2008;58:130-160.

5. Increased use of colorectal cancer tests-United States, 2002 and 2004. MMWR Morb Mortal Wkly Rep 2006;55:308311.

6. Gonik B, Jones T, Contreras D, Fasano N, Roberts C. The obstetrician-gynecologist's role in vaccine-preventable diseases and immunization. Obstet Gynecol 2000;96:81-84.

7. Kirk EP, Santa J, Heckler T, Collins M. Obstetriciangynecologists as primary care physicians: the Oregon experience-early perceptions regarding the effects of legislative action. Am J Obstet Gynecol 1998;178:1222-1228.

8. Morrison JC, Cowan BD, Hampton HL, Morton HH, Martin JN, Jr., McGehee RP. Medical practices of past graduates from one obstetric/gynecologic training program. South Med J 1998;91:227-230.

9. Scholle SH, Chang J, Harman J, McNeil M. Characteristics of patients seen and services provided in primary care visits in obstetrics/gynecology: data from NAMCS and NHAMCS. Am J Obstet Gynecol 2004;190:1119-1127.

10. Laube DW, Ling FW. Primary care in obstetrics and gynecology resident education: a baseline survey of residents' perceptions and experiences. Obstet Gynecol 1999;94:632636.

11. ACOG Committee Opinion No. 357: primary and preventive care: periodic assessments. Obstet Gynecol 2006;108:16151622.

12. Musinski SE. Colorectal cancer screening by obstetriciangynecologists. Am J Obstet Gynecol 2001;184:1054-1056.

13. Lewis BG, Halm EA, Marcus SM, Korenstein D, Federman AD. Preventive services use among women seen by gynecologists, general medical physicians, or both. Obstet Gynecol 2008;111:945-952.

14. Mandel JS, Bond JH, Church TR, et al. Reducing mortality from colorectal cancer by screening for fecal occult blood. Minnesota Colon Cancer Control Study. N Engl J Med 1993; 328:1365-1371.

15. Hardcastle JD, Chamberlain JO, Robinson MH, et al. Randomised controlled trial of faecal-occult-blood screening for colorectal cancer. Lancet 1996;348:1472-1477.

16. Jorgensen OD, Kronborg O, Fenger C. A randomised study of screening for colorectal cancer using faecal occult blood testing: results after 13 years and seven biennial screening rounds. Gut 2002;50:29-32.

17. Selby JV, Friedman GD, Quesenberry CP, Jr., Weiss NS. A case-control study of screening sigmoidoscopy and mortality from colorectal cancer. N Engl J Med 1992;326:653-657.

18. Newcomb PA, Norfleet RG, Storer BE, Surawicz TS, Marcus PM. Screening sigmoidoscopy and colorectal cancer mortality. I Natl Cancer Inst 1992;84:1572-1575.

19. Muller AD, Sonnenberg A. Prevention of colorectal cancer by flexible endoscopy and polypectomy. A case-control study of 32,702 veterans. Ann Intern Med 1995;123:904-910.
20. Winawer SJ, Zauber AG, Ho MN, et al. Prevention of colorectal cancer by colonoscopic polypectomy. The National Polyp Study Workgroup. N Engl J Med 1993;329:1977-1981.

21. Citarda F, Tomaselli G, Capocaccia R, Barcherini S, Crespi M. Efficacy in standard clinical practice of colonoscopic polypectomy in reducing colorectal cancer incidence. Gut 2001;48:812-815.

22. Thiis-Evensen E, Hoff GS, Sauar J, Langmark F, Majak BM, Vatn MH. Population-based surveillance by colonoscopy: effect on the incidence of colorectal cancer. Telemark Polyp Study I. Scand J Gastroenterol 1999;34:414-420.

23. Inadomi JM HK, Bernard L, Tang TS. Development of a patient-based experience survey for preference assessment of gastrointestinal procedures. Am J Gastroenterol 2002;97: S240-S241.

24. Menees SB, Inadomi JM, Korsnes S, Elta GH. Women patients' preference for women physicians is a barrier to colon cancer screening. Gastrointest Endosc 2005;62:219-223.

25. Lewis JD, Asch DA, Ginsberg GG, et al. Primary care physicians' decisions to perform flexible sigmoidoscopy. I Gen Intern Med 1999;14:297-302.

26. Hawley ST, Levin B, Vernon SW. Colorectal cancer screening by primary care physicians in two medical care organizations. Cancer Detect Prev 2001;25:309-318.

27. Collins JF, Lieberman DA, Durbin TE, Weiss DG. Accuracy of screening for fecal occult blood on a single stool sample obtained by digital rectal examination: a comparison with recommended sampling practice. Ann Intern Med 2005;142: $81-85$.

28. Griffith KA, McGuire DB, Royak-Schaler R, Plowden KO, Steinberger EK. Influence of family history and preventive health behaviors on colorectal cancer screening in African Americans. Cancer 2008;113:276-285.

29. Brawarsky P, Brooks DR, Mucci LA, Wood PA. Effect of physician recommendation and patient adherence on rates of colorectal cancer testing. Cancer Detect Prev 2004;28:260268.

30. Mandelson MT, Curry SJ, Anderson LA, et al. Colorectal cancer screening participation by older women. Am J Prev Med 2000;19:149-154.

31. Lewis SF, Jensen NM. Screening sigmoidoscopy. Factors associated with utilization. I Gen Intern Med 1996;11:542544.

32. Kelly RB, Shank JC. Adherence to screening flexible sigmoidoscopy in asymptomatic patients. Med Care 1992;30: 1029-1042.

33. Myers RE, Trock BJ, Lerman C, Wolf T, Ross E, Engstrom PF. Adherence to colorectal cancer screening in an HMO population. Prev Med 1990;19:502-514.

34. Weitzman ER, Zapka J, Estabrook B, Goins KV. Risk and reluctance: understanding impediments to colorectal cancer screening. Prev Med 2001;32:502-513.

35. Breen N, Wagener DK, Brown ML, Davis WW, BallardBarbash R. Progress in cancer screening over a decade: results of cancer screening from the 1987, 1992, and 1998 National Health Interview Surveys. J Natl Cancer Inst 2001;93:17041713.

36. Brown ML, Potosky AL, Thompson GB, Kessler LG. The knowledge and use of screening tests for colorectal and prostate cancer: data from the 1987 National Health Interview Survey. Prev Med 1990;19:562-574.

37. Harris MA, Byles JE. A survey of screening compliance among first-degree relatives of people with colon cancer in New South Wales. I Med Screen 1997;4:29-34. 
38. Codori AM, Petersen GM, Miglioretti DL, Boyd P. Health beliefs and endoscopic screening for colorectal cancer: potential for cancer prevention. Prev Med 2001;33:128-136.

39. Madlensky L, Esplen MJ, Gallinger S, McLaughlin JR, Goel V. Relatives of colorectal cancer patients: factors associated with screening behavior. Am J Prev Med 2003;25:187-194.

40. Hsia J, Kemper E, Kiefe C, et al. The importance of health insurance as a determinant of cancer screening: evidence from the Women's Health Initiative. Prev Med 2000;31:261-270.

41. Lemon S, Zapka J, Puleo E, Luckmann R, Chasan-Taber L. Colorectal cancer screening participation: comparisons with mammography and prostate-specific antigen screening. Am J Public Health 2001;91:1264-1272.

42. Thrasher JF, Cummings KM, Michalek AM, Mahoney MC, Moysich KB, Pillittere DM. Colorectal cancer screening among individuals with and without a family history. I Public Health Manag Pract 2002;8:1-9.

43. Manne S, Markowitz A, Winawer S, et al. Correlates of colorectal cancer screening compliance and stage of adoption among siblings of individuals with early onset colorectal cancer. Health Psychol 2002;21:3-15.
44. Harewood GC, Wiersema MJ, Melton LJ, III. A prospective, controlled assessment of factors influencing acceptance of screening colonoscopy. Am J Gastroenterol 2002;97:31863194.

45. Shapiro JA, Seeff LC, Nadel MR. Colorectal cancer-screening tests and associated health behaviors. Am J Prev Med 2001; 21:132-137.

46. Mayer-Oakes SA, Atchison KA, Matthias RE, De Jong FJ, Lubben J, Schweitzer SO. Mammography use in older women with regular physicians: what are the predictors? Am J Prev Med 1996;12:44-50.

47. Ryerson AB, Miller JW, Eheman CR, Leadbetter S, White MC. Recent trends in U.S. mammography use from 2000-2006: A population based analysis. Prev Med 2008;47:477-482.

Address correspondence to: Stacy B. Menees, M.D. 3912 Taubman Center, SPC 5362 Ann Arbor, MI 48109-5362

E-mail: sbartnik@med.umich.edu 


\section{Appendix 1}

Date:

Age:

Office:

Practitioner you are seeing today, please check all that apply: Male Female

Physician Nurse-practitioner

1. Ethnic group (please check all that apply) Caucasian

Asian

Black or African American

American Indian/Alaska Native

Latino or Hispanic

2. Marital status:

Married

Single

3. Employment status:

Currently working

Not employed

Retired

Other: please list:

4. Do you have any kind of healthcare coverage?

Yes

No

5. Do you consider your gynecologist to be your primary physician?

Yes

$\leq$ No (If no, please list:

6. Have you had any of the following? (Check all that apply)

Mammogram in the last 2 years

Pap smear in the last 2 years

No pap smear since I had a hysterectomy (removal of uterus by surgery)
7. Have you had any of the following cancers? (Check all that apply) Breast cancer

Ovarian/uterine cancer

Colon cancer

8. Has your gynecologist/nurse-practitioner recommended colon cancer screening for you? (Tests include a colonoscopy, stool cards, flexible sigmoidoscopy, or a radiology test called a barium enema. A colonoscopy and flexible sigmoidoscopy are medical procedures performed with an instrument that is guided through your colon)

Yes

No

9. Has any doctor recommended colon cancer screening to you? Yes No

10. Which doctor recommended you to have colon cancer screening? Primary care doctor Gynecologist/nurse practitioner Other

11. Have you undergone any of the following? (Circle all that apply) Stool tests in last year

Flexible sigmoidoscopy in last 5 years

Colonoscopy in last 10 years

Barium enema in last 5 years

12. Do you know someone who has colon cancer?

Yes

No

13. Do you have a family history of colon cancer or colon polyps? Yes No

14. Are you planning on having colon cancer screening? Yes No 
